\title{
Airway exposure to perfluorooctanoate exacerbates airway hyperresponsiveness and downregulates glucocorticoid receptor expression in asthmatic mice
}

\author{
Zeyu Zeng", Weihui Ma", Ran Zhao, Xiaoyan Dong \\ Department of Respiratory Medicine, Shanghai Children's Hospital, Shanghai Jiao Tong University, Shanghai, China \\ Contributions: (I) Conception and design: Z Zeng, W Ma; (II) Administrative support: X Dong; (III) Provision of study materials or patients: Z Zeng, \\ W Ma, R Zhao; (IV) Collection and assembly of data: Z Zeng, W Ma; (V) Data analysis and interpretation: Z Zeng, W Ma; (VI) Manuscript writing: \\ All authors; (VII) Final approval of manuscript: All authors. \\ "These authors contributed equally to this work. \\ Correspondence to: Xiaoyan Dong. Department of Respiratory Medicine, Shanghai Children's Hospital, Shanghai Jiao Tong University, 355 Luding \\ Rd, Shanghai 200062, China. Email: dongxy@shchildren.com.cn.
}

\begin{abstract}
Background: Multiple environmental risk factors play a vital role in the pathogenesis of asthma, which contribute to the phenotypic expression of asthma. Perfluorooctanoate (PFOA) is the most common and abundant perfluorocarbon (PFC) in humans, and it has been detected in water and the atmosphere worldwide. Glucocorticoid receptor (GR) is considered to exert a protective effect on asthma and is associated with the sensitivity to glucocorticoids. Dermal or oral exposure to PFOA has been shown to contribute various effects on airway inflammation in individuals with ovalbumin (OVA)-induced asthma. Notably, airway exposure has a critical contribution to the pathogenesis of asthma. However, the effect of airway exposure to PFOA on airway hyperresponsiveness (AHR) in patients with asthma is not currently understood.
\end{abstract}

Methods: BALB/c mice were administered OVA to induce asthma. PFOA was then administered intratracheally to OVA-induced mice for seven days. Then we assessed the effect of airway exposure to PFOA on AHR and the regulation of the GR expression in asthmatic mice.

Results: The results showed aggravated AHR and T helper type 2 (Th2) airway inflammation in asthmatic mice. Furthermore, these mice show a substantial decrease in the expression of the GR mRNA and protein.

Conclusions: These data strongly suggest that acute airway exposure to PFOA leads to Th2-related AHR and decreases GR expression, which may increase the difficulty in the treatment of asthma.

Keywords: Perfluorooctanoate (PFOA); airway hyperresponsiveness (AHR); glucocorticoid receptor (GR); asthma

Submitted Aug 18, 2020. Accepted for publication Dec 23, 2020.

doi: $10.21037 /$ tp-20-246

View this article at: http://dx.doi.org/10.21037/tp-20-246

\section{Introduction}

Asthma is one of the most common chronic inflammatory diseases of the airways occurring in both children and adults, and it involves multiple inflammatory cells and inflammatory mediators. Airway hyperresponsiveness (AHR) is one of the primary features of asthma. Many factors, such as chemical factors, infection factors, and intrauterine and infant exposure, affect the body's susceptibility to asthma. With the acceleration of industrial development and urbanization, the role of environmental factors in the pathogenesis of asthma has attracted increasing attention (1-3). Perfluorooctanoic acid (PFOA) is a typical perfluoro compound. Because of its high chemical stability, thermal stability, and strong hydrophobic and oleophobic properties, 
it is widely applied in various fields of production and people's lives (4). PFOA is not easily degraded, and its half-life in the human body is 3.8 years (5). PFOA exerts various biological toxic effects on the liver, immune system, reproductive system, endocrine system, etc. (6), which is extremely harmful to animals and humans. An exposure study reported a statistically significant higher prevalence of asthma following prolonged exposure to PFOA in drinking water (7). Recently, researchers have detected PFOA in the atmosphere of Shenzhen, China and Madrid, Spain $(8,9)$. Perfluorinated compounds (PFCs), such as PFOA and perfluorooctanesulfonic acid (PFOS), have been detected in indoor dust (10), and volatile precursors were also detected in the room air (11-13). PFOA adsorbed on the surface of air and dust is the major route of PFOA exposure in humans. PFOA was positively correlated with asthma severity scores among patients with asthma $(14,15)$. Ryu and colleagues have clarified that the ingestion of a low dose of PFOA does not alter the severity of airway hyperresponsiveness (AHR) in OVA-induced mice. Nevertheless, other researchers have determined that serum PFOA levels are associated with impaired lung function among children with asthma (16), but the routes of PFOA exposure remain unclear. Since respiratory tract exposure has been a critical pathway involved in the pathogenesis of asthma, the effects of direct airway exposure to PFOA on AHR and airway inflammation in patients with asthma require further investigation.

Currently, inhaled glucocorticoids are the first-line treatment for asthma, and their anti-inflammatory effects are related to the structure and density of glucocorticoid receptors (GR). Elevated levels of glucocorticoid receptor are considered to exert anti-inflammatory and protective effects. Patients with severe asthma show reduced expression of GR (17). In contrast, patients with asthma might present resistance to corticosteroid treatment because of a reduction in GR signaling, as a decrease in the number of GR proteins or changes in the affinity of the glucocorticoid-binding GR may reduce the reactivity of glucocorticoids (18). Based on this evidence, GR plays very important roles in the pathogenesis and treatment of asthma. On the other hand, 11ß-hydroxysteroid dehydrogenase (11ß-HSD) type 1 catalyze the regeneration of active glucocorticoids (19), which increase the expression of GR. In our previous study, we have determined that PFOA is the inhibitor of 11ß-HSD1 (20). Consequently, we supposed that PFOA may cause a reduction in GR expression. However, the role of PFOA exposure as a causative factor of asthma and whether it will aggravate the reduction in GR expression in patients with asthma remain unclear and require further exploration.

Therefore, this study aimed to assess the effects of airway exposure to PFOA on AHR and GR expression in a mouse model of asthma.

We present the following article in accordance with the ARRIVE reporting checklist (available at http://dx.doi. org/10.21037/tp-20-246).

\section{Methods}

\section{Animals and treatments}

Thirty BALB/c mice (four to six weeks old, male) were randomly divided into five groups, including the sham, OVA, OVA+10 pg PFOA, OVA+50 pg PFOA, and OVA+100 pg PFOA groups. The OVA-induced asthma model was constructed as described in our previous study (21-23). Mice were sensitized by intraperitoneally administration of $0.01 \%$ OVA (10 $\mu \mathrm{g}$ OVA and $20 \mathrm{mg} \mathrm{Al}$ $(\mathrm{OH})_{3}$ gel dissolved in $0.1 \mathrm{~mL} \mathrm{NS}$ ) on days 1 and 13 . From day 25 , they were challenged with $1 \%$ OVA $(10 \mathrm{mg} / \mathrm{mL})$ aerosol for $30 \mathrm{~min}$ daily for 7 consecutive days. Sham group were sensitized and challenged with NS. Animal experiments were performed under a project license (Ethical code: wydw2016-0151) granted by Wenzhou Medical University Institutional Animal Care Committee, in compliance with the Association for Assessment and Accreditation of Laboratory Animal Care (AAALAC) guidelines for the care and use of animals. Mice were purchased from the SLAC Company (Shanghai, China) and housed under a specific pathogen-free (SPF) conditions with a constant temperature $\left(22 \pm 1{ }^{\circ} \mathrm{C}\right)$, suitable humidity $(50 \% \pm 1 \%)$ and a $12 \mathrm{~h}$ light/ dark cycle. PFOA (Sigma, United States) was dissolved in phosphate-buffered saline (PBS). PFOA (10, 50, and $100 \mathrm{pg}$ ) was administered intratracheally after each OVA (Sigma, United States) challenge. The concentration of PFCs in the atmosphere averaged $15 \mathrm{pg} / \mathrm{m}^{3}$, of which PFOA accounts for $35 \%$ (about $5.4 \mathrm{pg} / \mathrm{m}^{3}$ ) (9). The mice weight are calculated according to $30 \mathrm{~g}$, the tidal volume of $0.15 \mathrm{~mL}$, and the respiratory rate of 200 times per minute. Therefore, the doses of PFOA we used in this study are equivalent to inhaling PFOA from exposure to the atmosphere for about 10, 30 and 60 weeks, respectively. The volume of PBS used for each concentration of PFOA was $40 \mu \mathrm{L}$. Control animals received intranasal PBS (vehicle). 
Table 1 Primer sequence for reverse transcription quantitative real-time polymerase chain reaction (qRT-PCR)

\begin{tabular}{lcc}
\hline Gene & Forward primer (5'-3') & Reverse primer (5'-3') \\
\hline GR & TTCCCCATCACTTTTGTTTCG & GGTTTCTGCGTCTTCACCCTC \\
GAPDH & TGGCCTTCCGTGTTCCTAC & GAGTTGCTGTTGAAGTCGCA \\
\hline
\end{tabular}

\section{Lung function analysis}

Mice were anesthetized with an intraperitoneal injection of $1 \%$ pentobarbital sodium $(50 \mathrm{mg} / \mathrm{kg})$ within 24 hours after the last challenge. A tracheotomy was performed and baseline airway resistance $(\mathrm{Rn})$ was evaluated using a forced oscillation system (FlexiVent, SCIREQ Scientific Respiratory Equipment Inc., Montreal, Canada). Afterwards, increasing doses of methacholine (MCh) were administered and the corresponding Rn was measured as previously described $(21,24)$.

\section{Histopathological examination and transmission electron microscopy}

The lower segment of the right lung was fixed with $2.5 \%$ glutaraldehyde by immersion for transmission electron microscopy. Meanwhile, the middle section $(4 \mu \mathrm{m})$ of the right lung was fixed with formalin and embedded in paraffin for the histopathological examination. The total score of airway inflammation was assessed as described in a previous study (25).

\section{Enzyme-linked immunosorbent assay (ELISA)}

Serum IL-4, OVA-IgE and IFN- $\gamma$ concentrations were measured using a mouse/rat quantitative ELISA Kit (Boyun, Shanghai, China).

\section{Immunobistochemistry}

The lung tissues were fixed, sectioned, stained with hematoxylin (Thermo Shandon, PA, USA), and subjected to immunohistochemical staining with glucocorticoid receptor (GR) antibodies (Santa Cruz Biotechnology, USA). For quantitation, the optical densities of the GR protein were analyzed using Image-Pro Plus 6.0 software.

\section{Quantitative real-time reverse transcription polymerase chain reaction ( $q R T-P C R)$}

Total RNA was isolated from lung tissues using TRIzol reagent (Invitrogen, USA). The PrimeScript RT reagent kit (Takara Bio Inc., USA) was used to synthesize firststrand cDNAs. Thereafter, qRT-PCR was performed using Roche Lightcycler 480 SYBR Green (Roche, Switzerland). The relative levels of specific mRNAs were normalized to the expression of the Glyceraldehyde-3-phosphate dehydrogenase (GAPDH) mRNA using the $\Delta \Delta \mathrm{Ct}$ method. All primers are listed in Table 1.

\section{Statistical analysis}

All data are expressed as mean values \pm standard deviation (SD) and were statistically analyzed using one-way ANOVA. $\mathrm{P}<0.05$ was considered to indicate statistical significance. The experiments were performed in triplicate.

\section{Results}

PFOA exacerbates the airway hyperresponsiveness (AHR) of asthmatic mice

OVA, OVA+10 pg PFOA and OVA+50 pg PFOA groups showed higher values of baseline $\mathrm{Rn}$ and MCh-induced AHR than the sham group $(\mathrm{P}<0.01)$. Nevertheless, baseline $\mathrm{Rn}$ and MCh AHR values were significantly increased when the dose of PFOA increased to $100 \mathrm{pg}$ compared with the OVA group $(\mathrm{P}<0.01)$ (Table 2 and Figure 1).

\section{Airway exposure to $\mathrm{PFOA}$ aggravates the airway inflammation and destroys the ultrastructure of the lung tissue in OVA-induced mice}

As indicated in Figure 2, the OVA, OVA +10 pg PFOA and OVA+50 pg PFOA groups exhibited more severe trachea and perivascular cellular infiltration than the sham group. Significant differences were not observed among the OVA, OVA $+10 \mathrm{pg} \mathrm{PFOA}$ and OVA $+50 \mathrm{pg}$ PFOA groups. However, the OVA+100 pg PFOA group showed obviously increased inflammation and thickening of the airway wall compared with mice in the OVA group $(\mathrm{P}<0.01)$. Additionally, electron microscopy of lung tissue showed vacuolated and loose lamellar bodies, disordered 
Table 2 Perfluorooctanoate (PFOA) increased the baseline airway resistance $(\mathrm{Rn})$ of asthmatic mice

\begin{tabular}{llc}
\hline Group & $\mathrm{n}$ & $\mathrm{Rn}\left(\mathrm{cmH}_{2} \mathrm{O} / \mathrm{mL} / \mathrm{s}\right)$ \\
\hline Sham & 6 & $0.3753 \pm 0.0371$ \\
Ovalbumin (OVA) & 6 & $0.5787 \pm 0.0206^{\star}$ \\
OVA+10 pg PFOA & 6 & $0.5992 \pm 0.0182^{*}$ \\
OVA+50 pg PFOA & 6 & $0.6146 \pm 0.0415^{\star}$ \\
OVA+100 pg PFOA & 6 & $0.8582 \pm 0.1087^{\#}$ \\
\hline
\end{tabular}

Mice were exposed to aerosolized saline using a Mouse ventilator with the forced oscillation technique, and Baseline $\mathrm{Rn}$ was then detected. Data are mean \pm standard deviation (SD) $(n=6)$. ${ }^{*} P<0.01$ compared with the sham group; ${ }^{~} \mathrm{P}<0.01$ compared with the OVA group.

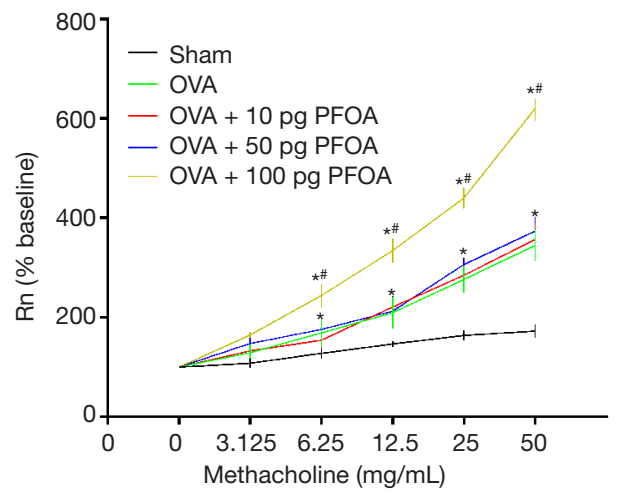

Figure 1 Perfluorooctanoate (PFOA) exacerbates airway hyperresponsiveness (AHR) in ovalbumin (OVA)-induced mice. After administered with increasing doses of methacholine (MCh) $(3.125,6.25,12.5,25$, and $50 \mathrm{mg} / \mathrm{mL})$, the corresponding airway resistance $(\mathrm{Rn})$ of each mice was measured, and the percentages relative to the baseline $\mathrm{Rn}$ are shown. Data are presented as means \pm standard deviation $(\mathrm{SD})(\mathrm{n}=6) .{ }^{*} \mathrm{P}<0.01$ compared with the sham group; ${ }^{\#} \mathrm{P}<0.05$ compared with the OVA group.

cilia and swollen mitochondria in the OVA, OVA+10 pg PFOA, OVA+50 pg PFOA and OVA+100 pg PFOA groups compared with the sham group. Furthermore, PFOA was engulfed by macrophages the in OVA+100 pg PFOA group (Figure 3).

\section{Effects of airway exposure to PFOA on serum levels of IL- 4, OVA-IgE and IFN- ${ }^{\gamma}$ in OVA-induced mice}

As indicated in Figure 4, the serum levels of IL-4 and OVA-IgE were markedly increased in the OVA (IL-
4, $24.39 \pm 3.43 \mathrm{pg} / \mathrm{mL}$; OVA-IgE, $40.22 \pm 6.52 \mathrm{U} / \mathrm{mL})$, OVA+10 pg PFOA (IL-4, 24.67 $\pm 4.62 \mathrm{pg} / \mathrm{mL}$; OVA-IgE, $40.11 \pm 4.92 \mathrm{U} / \mathrm{mL}$ ) and OVA $+50 \mathrm{pg}$ PFOA groups (IL4, $22.32 \pm 8.27 \mathrm{pg} / \mathrm{mL}$; OVA-IgE, 41.20 $\pm 5.29 \mathrm{U} / \mathrm{mL}, \mathrm{P}<0.01)$ compared with the sham group (IL-4, $15.74 \pm 0.53 \mathrm{pg} / \mathrm{mL}$; OVA-IgE, $8.05 \pm 1.48 \mathrm{U} / \mathrm{mL}$ ). However, higher serum IL-4 and OVA-IgE levels were observed in the OVA+100 pg PFOA group (IL-4, 29.70 $\pm 5.02 \mathrm{pg} / \mathrm{mL}$; OVA-IgE, 58.42 $\pm 4.94 \mathrm{U} / \mathrm{mL}$ ) compared with the OVA group $(\mathrm{P}<0.01)$. In contrast, the OVA $(23.52 \pm 3.40 \mathrm{pg} / \mathrm{mL}), \mathrm{OVA}+10 \mathrm{pg}$ PFOA $(23.59 \pm 3.29 \mathrm{pg} / \mathrm{mL})$ and OVA $+50 \mathrm{pg}$ PFOA groups $(20.66 \pm 2.25 \mathrm{pg} / \mathrm{mL})$ exhibited significantly reduced serum IFN- $\gamma$ levels compared with the sham group $(36.64 \pm 5.96 \mathrm{pg} / \mathrm{mL}, \mathrm{P}<0.01)$. However, lower serum IFN- $\gamma$ levels were observed in the OVA+100 pg PFOA group $(18.15 \pm 0.68 \mathrm{pg} / \mathrm{mL})$ than in the OVA group $(\mathrm{P}<0.01)$.

\section{Airway exposure to PFOA reduces the levels of the GR protein in the lungs of asthmatic mice}

We employed immunohistochemistry and western blotting to examine the levels of the GR protein in mice after OVA and PFOA exposure. The results of immunohistochemical staining showed significantly decreased levels of the GR protein in lung tissue samples from the OVA $(0.1564 \pm 0.0228)$, OVA +10 pg PFOA $(0.1598 \pm 0.0154)$, OVA $+50 \mathrm{pg}$ PFOA $(0.1501 \pm 0.0068)$ and $\mathrm{OVA}+100 \mathrm{pg}$ PFOA $(0.1112 \pm 0.0118)$ groups compared with the tissue samples from the sham group $(0.2513 \pm 0.0234, \mathrm{P}<0.01)$. Interestingly, a significant reduction of the GR protein level in lung tissue specimens were observed in the OVA+100 pg PFOA group compared with the OVA group $(\mathrm{P}<0.01)$ (Figure 5).

\section{Inbibitory effects of airway exposure to PFOA on the level of the GR $m R N A$ in the lungs of asthmatic mice}

The level of the GR mRNA was examined after various treatments. Interestingly, the expression of the GR mRNA was markedly reduced in the OVA $(0.17 \pm 0.02), \mathrm{OVA}+10$ pg PFOA $(0.13 \pm 0.06)$, OVA +50 pg PFOA $(0.09 \pm 0.04)$ and OVA $+100 \mathrm{pg}$ PFOA $(0.04 \pm 0.01)$ groups compared with the sham group $(1.03 \pm 0.16$; all $\mathrm{P}<0.01)$. However, these values were lower in the OVA+100 pg PFOA group than in the OVA group $(\mathrm{P}<0.01)$ (Figure 6).

\section{Discussion}

In the present study, we examined the effect of airway 


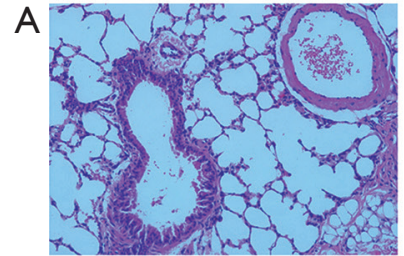

Sham

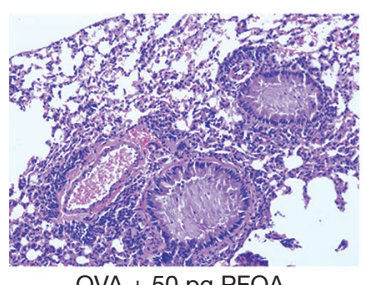

OVA +50 pg PFOA

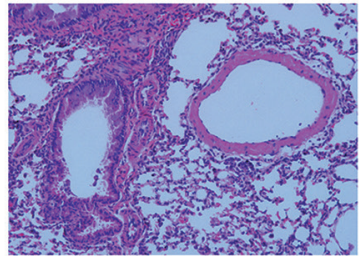

OVA

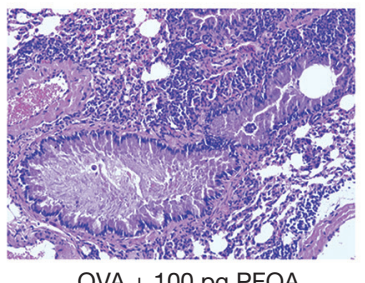

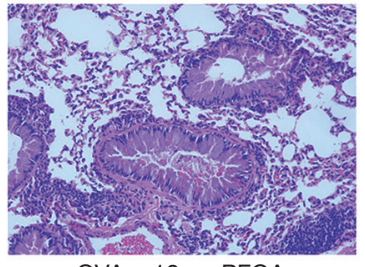

OVA + 10 pg PFOA

\section{B}

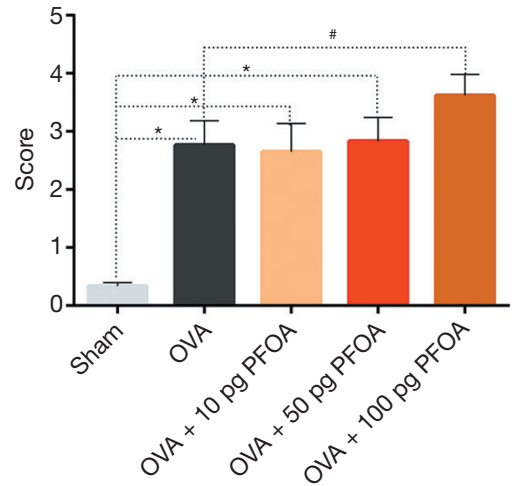

Figure 2 Airway exposure to perfluorooctanoate (PFOA) aggravates the airway inflammation in ovalbumin (OVA)-induced mice. (A) Representative photographs of HE staining (lung tissue, $\times 200$ magnification). (B) Scores of airway inflammation. Data are expressed as means \pm standard deviation (SD) $(\mathrm{n}=6)$. ${ }^{*} \mathrm{P}<0.01$ compared with the sham group; ${ }^{\#} \mathrm{P}<0.01$ compared with the OVA group.

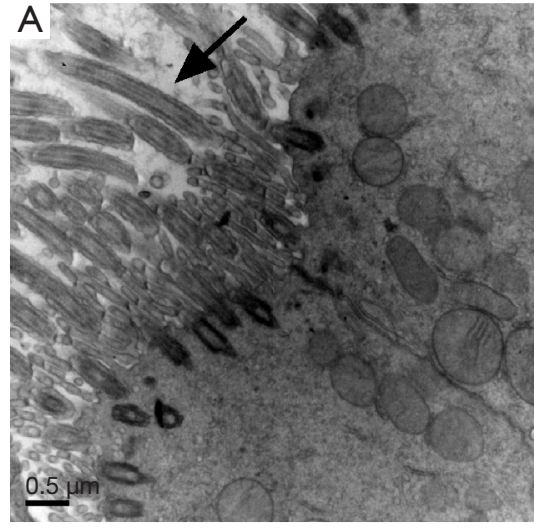

Sham

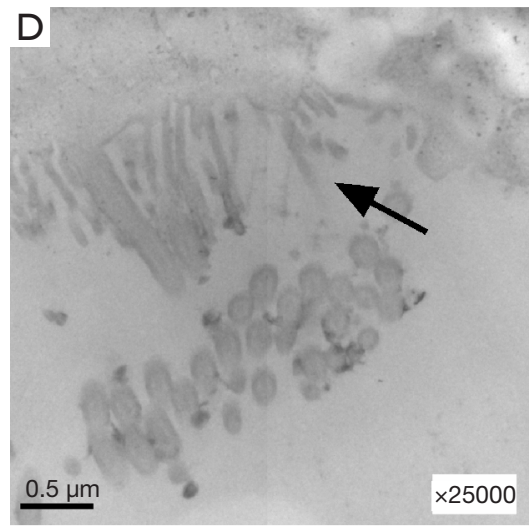

OVA +10 pg PFOA

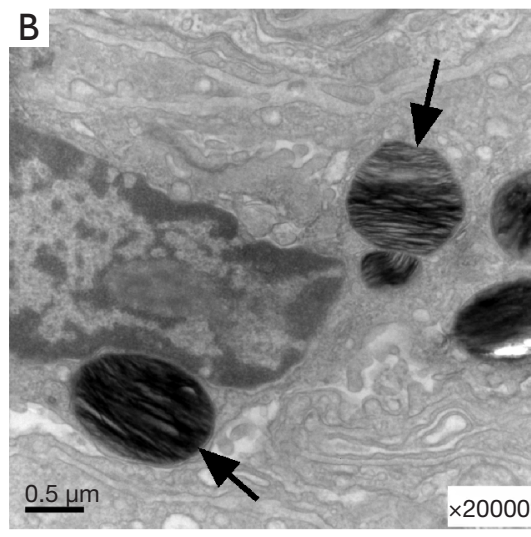

Sham

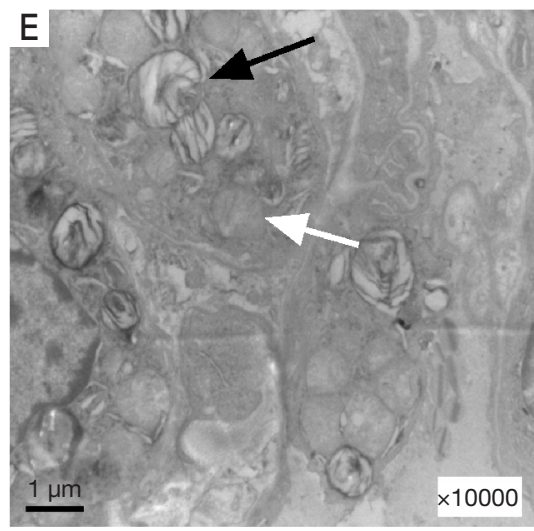

OVA +50 pg PFOA

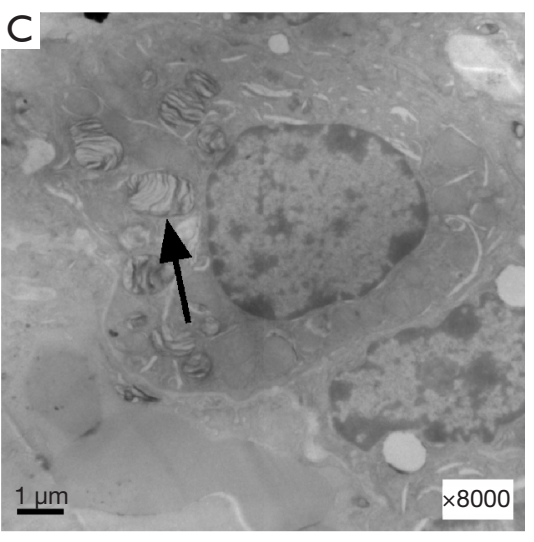

OVA

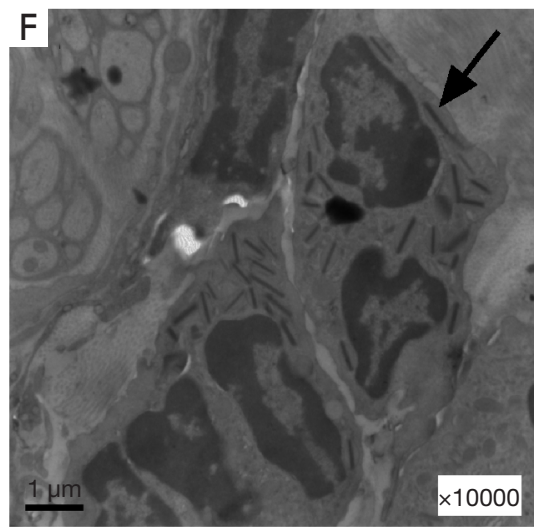

OVA +100 pg PFOA

Figure 3 Perfluorooctanoate (PFOA) destroys the ultrastructure of the lung tissue in asthmatic mice. (A) Cilia of a normal cell (black arrow), (B) compact lamellar body (black arrow), (C) loose lamellar body (black arrow), (D) disorder cilia (black arrow), (E) loose lamellar body (black arrow) and swollen organelle (white arrow), and (F) PFOA engulfed by macrophages (black arrow). 

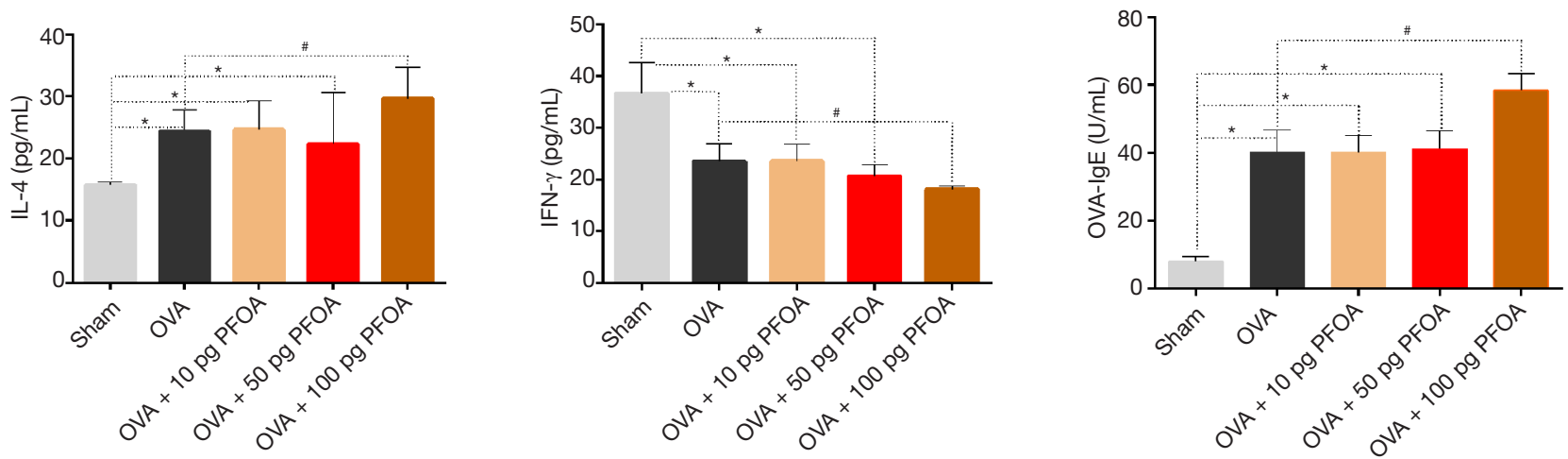

Figure 4 Effects of airway exposure to perfluorooctanoate (PFOA) on serum IL-4, ovalbumin (OVA)-IgE, and interferon (IFN)- $\gamma$ levels in OVA-induced mice. Serum levels of IL-4, OVA-IgE, and IFN- $\gamma$ were determined using Enzyme-linked immunosorbent assay (ELISA). Data are expressed as means \pm standard deviation $(\mathrm{SD})(\mathrm{n}=6)$. ${ }^{*} \mathrm{P}<0.01$ compared with the sham group; ${ }^{*} \mathrm{P}<0.01$ compared with the $\mathrm{OVA}$ group.
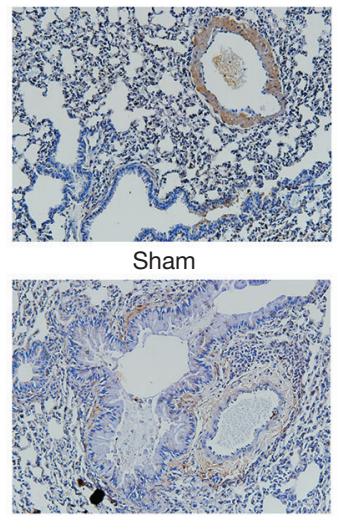

OVA +50 pg PFOA
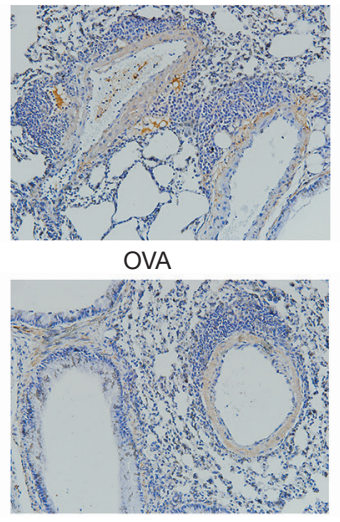

OVA +100 pg PFOA

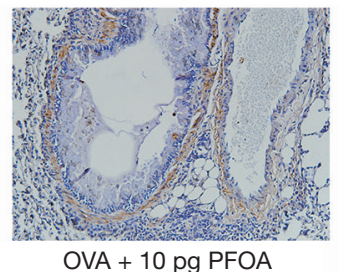

OVA + 10 pg PFOA

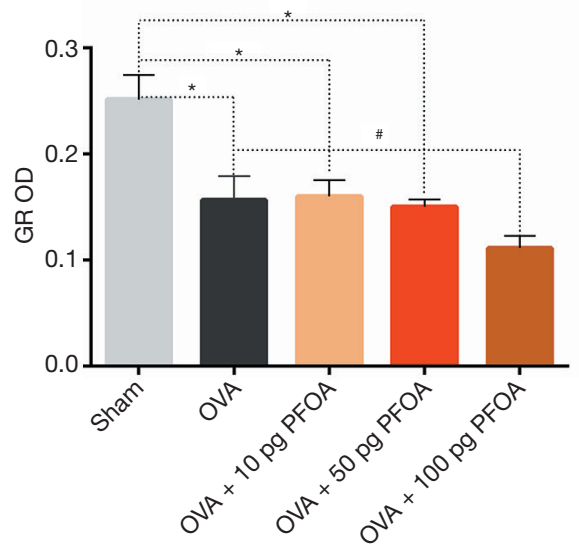

Figure 5 Effects of airway exposure to perfluorooctanoate (PFOA) on levels of the glucocorticoid receptor (GR) protein in the mice lung. (A) Levels of the GR protein were determined using immunohistochemistry. (B) Semiquantitative analysis of levels of the GR protein using Image-Pro Plus software. Data are presented as means \pm standard deviation $(\mathrm{SD})(\mathrm{n}=6) .{ }^{*} \mathrm{P}<0.01$ compared with the sham group; ${ }^{\#} \mathrm{P}<0.01$ compared with the OVA group.

exposure to PFOA on AHR and GR expression in asthmatic mice. Intratracheal PFOA administration exacerbated the airway hyperresponsiveness of OVA-induced asthmatic mice. Moreover, PFOA significantly increased the IL-4 and OVA-IgE levels and reduced the IFN- $\gamma$ level in the serum, aggravating airway inflammation in OVA-induced asthmatic mice. Interestingly, airway exposure to PFOA did cause a further decrease in the expression of the GR mRNA and protein in asthmatic mice.

Numerous studies have determined the relationship between PFOA and asthma. According to one study, exposure to ingested PFOA resulted in increased $\mathrm{Rn}$ and MCh AHR values in a non-OVA-induced mouse model; however, exposure to ingested PFOA did not alter the severity of AHR in an OVA-induced mouse model (26). Another study reported an association between serum PFOA levels and impaired lung function in children with asthma (16). Nevertheless, Fairley (27) showed that dermal exposure to PFOA exacerbates AHR in OVA-induced mice and increases the responsivity of the airway to OVA and other allergens. Based on this evidence, different routes of PFOA exposure may exert different effects on AHR in individuals with asthma. Airway exposure is a crucial contributor to the onset of asthma; however, the effect of airway exposure to PFOA on AHR in patients with asthma has not been elucidated. Interestingly, in our study, baseline 


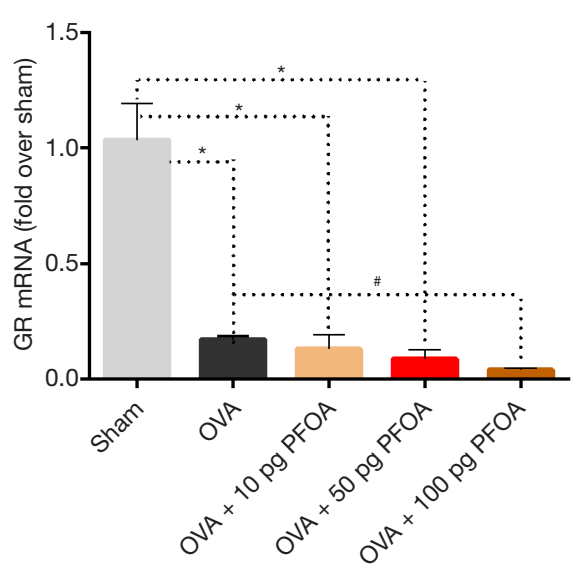

Figure 6 Effects of airway exposure to perfluorooctanoate (PFOA) on the expression of the glucocorticoid receptor (GR) mRNA in the lung. The level of the GR mRNA in the lung was determined using quantitative real-time reverse transcription polymerase chain reaction (qRT-PCR). Data are presented as means \pm standard deviation (SD) $(n=6) .{ }^{*} \mathrm{P}<0.01$ compared with the sham group; ${ }^{\#} \mathrm{P}<0.01$ compared with the OVA group.

$\mathrm{Rn}$ and MCh AHR values were significantly increased after 7 days of intratracheal administration of a high dose of PFOA. Our study is the first to show that airway exposure to PFOA is a risk factor for more severe AHR in an animal model of OVA-induced asthma.

Airway inflammation is one of the primary causes of AHR. T helper type 2 (Th2) cells play a vital role in the airway inflammation associated with asthma (28). IL-4 is a hallmark cytokine of Th2 cells, which is involved in IgE production, AHR and airway eosinophilia. Meanwhile, IFN- $\gamma$, which is derived from Th1 cells, promotes the differentiation of Th0 cells to Th1 cells and inhibits the function of Th2 cells. As shown in the study by Dong (29), $\mathrm{PFC}$ exposure is associated with an obvious imbalance in Th1/Th2 cytokines, with amplified Th2 and weakened Th1 responses, leading to the aggravation of the Th2-mediated inflammatory response. According to Fairley (27), dermal exposure to PFOA increases serum IgE levels and causes an exaggerated response to ovalbumin. Prenatal exposure to PFOA and PFOS is associated with higher cord blood levels of IgE (30). Higher serum PFOA levels are associated with higher levels of total IgE in children (31). Based on this evidence, we investigated whether airway exposure to PFOA would enhance the Th2 response in OVA-induced asthmatic mice. As shown above, elevated IL-4 and OVA$\mathrm{IgE}$ and decreased IFN- $\gamma$ levels were detected in mice in the OVA group. Interestingly, mice in the OVA+100 pg PFOA group (which displayed a more severe AHR than the OVA group) showed higher serum IL-4 and OVA-IgE levels and lower serum IFN- $\gamma$ levels than mice in the OVA group. A pathological examination and electron microscopy of lung tissues also showed increased inflammation, airway wall thickening and the destruction of cellular structures. Thus, airway exposure to PFOA may intensify the Th2 response to allergens in individuals with asthma in a dosedependent manner. However, Ryu (26) found that chronic gastrointestinal exposure to PFOA increases IFN- $\gamma$ levels in the alveolar lavage fluid of embryonic and neonatal mice, suggesting that PFOA may also be implicated in Th1-mediated immune responses. This discrepancy may be related to the use of different PFOA exposure routes and the duration of exposure. The potential molecular mechanism requires further clarification.

The anti-inflammatory effects of endogenous glucocorticoids are associated with the structure and density of GR. The mechanisms underlying the antiinflammatory effects of GR include interactions with glucocorticoid response elements, such as SLPI MKP1 and GILZ, to promote the transcription of antiinflammatory genes (32), interactions with CBP to inhibit the transcriptional activity of transcription factors such as NF- $\mathrm{KB}$ (33), and an increase in the expression of TTP to inhibit the expression of inflammatory factors, such as TNF- $\alpha$ (34). Increased expression of glucocorticoid receptor is considered to exert protective effects. Patients with asthma often present a decrease in the expression of GR (17). Exercise might increase GR expression and the levels of anti-inflammatory cytokines in a model of OVAinduced asthma (35). IL-4 inhibits the transfer of GR from peripheral monocytes into the nucleus (36), leading to enhanced Th2 type immune responses in individuals with asthma. GR is expressed in almost all cells, but it is present as different isoforms (37). Nevertheless, researchers have not yet determined whether PFOA aggravates the decrease in GR expression in patients with asthma. Based on accumulating evidence, patients with asthma present resistance to corticosteroid treatment that may be attributed to a reduction in GR expression in the airways (18). In our study, decreased expressions of the GR mRNA and protein was observed in OVA-induced mice; however, there was a further decrease in the expressions of the GR mRNA and protein level after airway exposure to PFOA. Therefore, airway exposure to PFOA may precipitate steroid resistance in patients with asthma. However, this hypothesis should be 
further confirmed in future studies.

Overall, airway exposure to PFOA exacerbates airway hyperresponsiveness, enhances Th2-type immune response and downregulates GR expression in asthmatic mice. Although the current evidence does not suggest substantial accumulation and toxicity of PFCs (38), PFOA in the atmosphere could migrate from a long distance, which is a great hazard. PFCs have a wide global distribution, and the effect of PFOA in the atmosphere on respiratory diseases such as asthma has attracted increasing attention and deserves further exploration.

\section{Acknowledgments}

Funding: This work was sponsored by the National Natural Science Foundation of China grant (81971424) and Shanghai international science and Technology Cooperation Fund (No. 18410721300) and Medical-Engineering Cross Project of Shanghai Jiao Tong University (YG2017MS34).

\section{Footnote}

Reporting Checklist: The authors have completed the ARRIVE reporting checklist. Available at http://dx.doi. org/10.21037/tp-20-246

Data Sharing Statement: Available at http://dx.doi. org/10.21037/tp-20-246

Conflicts of Interest: All authors have completed the ICMJE uniform disclosure form (available at http://dx.doi. org/10.21037/tp-20-246). The authors have no conflicts of interest to declare.

Ethical Statement: The authors are accountable for all aspects of the work in ensuring that questions related to the accuracy or integrity of any part of the work are appropriately investigated and resolved. Animal experiments were performed under a project license (Ethical code: wydw2016-0151) granted by Wenzhou Medical University Institutional Animal Care Committee, in compliance with the Association for Assessment and Accreditation of Laboratory Animal Care (AAALAC) guidelines for the care and use of animals.

Open Access Statement: This is an Open Access article distributed in accordance with the Creative Commons
Attribution-NonCommercial-NoDerivs 4.0 International License (CC BY-NC-ND 4.0), which permits the noncommercial replication and distribution of the article with the strict proviso that no changes or edits are made and the original work is properly cited (including links to both the formal publication through the relevant DOI and the license). See: https://creativecommons.org/licenses/by-nc-nd/4.0/.

\section{References}

1. Guarnieri M, Balmes JR. Outdoor air pollution and asthma. Lancet 2014;383:1581-92.

2. Miller MD, Marty MA. Impact of environmental chemicals on lung development. Environ Health Perspect 2010;118:1155-64.

3. Kim HY, DeKruyff RH, Umetsu DT. The many paths to asthma: phenotype shaped by innate and adaptive immunity. Nat Immunol 2010;11:577-84.

4. Lindstrom AB, Strynar MJ, Libelo EL. Polyfluorinated compounds: past, present, and future. Environ Sci Technol 2011;45:7954-61.

5. Olsen GW, Burris JM, Ehresman DJ, et al. Halflife of serum elimination of perfluorooctanesulfonate, perfluorohexanesulfonate, and perfluorooctanoate in retired fluorochemical production workers. Environ. Health Perspect 2007;115:1298-305.

6. Butenhoff JL, Bjork JA, Chang SC, et al. Toxicological evaluation of ammonium perfluorobutyrate in rats: twentyeight-day and ninety-day oral gavage studies. Reprod Toxicol 2012;33:513-30.

7. Anderson-Mahoney P, Kotlerman J, Takhar H, et al. Self-reported health effects among community residents exposed to perfluorooctanoate. New Solut 2008;18:129-43.

8. Beser MI, Pardo O, Beltrán J, et al. Determination of perand polyfluorinated substances in airborne particulate matter by microwave-assisted extraction and liquid chromatography-tandem mass spectrometry. J Chromatogr A 2011;1218:4847-55.

9. Liu B, Zhang H, Yao D, et al. Perfluorinated compounds (PFCs) in the atmosphere of Shenzhen, China: Spatial distribution, sources and health risk assessment. Chemosphere 2015;138:511-8.

10. Haug LS, Huber S, Schlabach M, et al. Investigation on per- and polyfluorinated compounds in paired samples of house dust and indoor air from Norwegian homes. Environ Sci Technol 2011;45:7991-8. 
11. Shoeib M, Harner T, Webster GM, et al. Indoor sources of poly- and perfluorinated compounds (PFCS) in Vancouver, Canada: implications for human exposure. Environ Sci Technol 2011;45:7999-8005.

12. Stahl T, Mattern D, Brunn H. Toxicology of perfluorinated compounds. Environ Sci Eur 2011;23:38.

13. Stock NL, Lau FK, Ellis DA, et al. Polyfluorinated telomer alcohols and sulfonamides in the North American troposphere. Environ Sci Technol 2004;38:991-6.

14. Dong GH, Tung KY, Tsai CH, et al. Serum polyfluoroalkyl concentrations, asthma outcomes, and immunological markers in a case-control study of Taiwanese children. Environ Health Perspect 2013;121:507-13.

15. Humblet O, Diaz-Ramirez LG, Balmes JR, et al. Perfluoroalkyl chemicals and asthma among children 1219 years of age: NHANES (1999-2008). Environ Health Perspect 2014;122:1129-33.

16. Qin XD, Qian ZM, Dharmage SC, et al. Association of perfluoroalkyl substances exposure with impaired lung function in children. Environ Res 2017;155:15-21.

17. Chang PJ, Bhavsar PK, Michaeloudes C, et al. Corticosteroid insensitivity of chemokine expression in airway smooth muscle of patients with severe asthma. J Allergy Clin Immunol 2012;130:877-85.e5.

18. Persson H, Kwon AT, Ramilowski JA, et al. Transcriptome analysis of controlled and therapy-resistant childhood asthma reveals distinct gene expression profiles. J Allergy Clin Immunol 2015;136:638-48.

19. Chapman K, Holmes M, Seckl J. 11ß-hydroxysteroid dehydrogenases: intracellular gate-keepers of tissue glucocorticoid action. Physiol Rev 2013;93:1139-206.

20. Ye L, Zhao B, Cai XH, et al. The inhibitory effects of perfluoroalkyl substances on human and rat $11 \beta$-hydroxysteroid dehydrogenase 1 . Chem Biol Interact 2012;195:114-8.

21. Zeng Z, Lin X, Zheng R, et al. Celastrol Alleviates Airway Hyperresponsiveness and Inhibits Th17 Responses in Obese Asthmatic Mice. Front Pharmacol 2018;9:49.

22. Zhang W, Nie $Y$, Chong L, et al. PI3K and Notch signal pathways coordinately regulate the activation and proliferation of $\mathrm{T}$ lymphocytes in asthma. Life Sci 2013;92:890-5.

23. Chong L, Zhang W, Nie Y, et al. Protective effect of curcumin on acute airway inflammation of allergic asthma in mice through Notch1-GATA3 signaling pathway. Inflammation 2014;37:1476-85.

24. Zeng $\mathrm{Z}$, Wang $\mathrm{L}, \mathrm{Ma} \mathrm{W}$, et al. Inhibiting the Notch signaling pathway suppresses Th17-associated airway hyperresponsiveness in obese asthmatic mice. Lab Invest 2019;99:1784-94.

25. Zhang $W$, Zhang $X$, Sheng A, et al. $\gamma$-Secretase Inhibitor Alleviates Acute Airway Inflammation of Allergic Asthma in Mice by Downregulating Th17 Cell Differentiation. Mediators Inflamm 2015;2015:258168.

26. Ryu MH, Jha A, Ojo OO, et al. Chronic exposure to perfluorinated compounds: Impact on airway hyperresponsiveness and inflammation. Am J Physiol Lung Cell Mol Physiol 2014;307:L765-74.

27. Fairley KJ, Purdy R, Kearns S, et al. Exposure to the immunosuppressant, perfluorooctanoic acid, enhances the murine $\operatorname{IgE}$ and airway hyperreactivity response to ovalbumin. Toxicol Sci 2007;97:375-83.

28. Holgate ST. Innate and adaptive immune responses in asthma. Nat Med 2012;18:673-83.

29. Dong GH, Liu MM, Wang D, et al. Sub-chronic effect of perfluorooctanesulfonate (PFOS) on the balance of type 1 and type 2 cytokine in adult C57BL6 mice. Arch Toxicol 2011;85:1235-44.

30. Wang IJ, Hsieh WS, Chen CY, et al. The effect of prenatal perfluorinated chemicals exposures on pediatric atopy. Environ Res 2011;111:785-91.

31. Stein CR, McGovern KJ, Pajak AM, et al. Perfluoroalkyl and polyfluoroalkyl substances and indicators of immune function in children aged 12-19 y: National Health and Nutrition Examination Survey. Pediatr Res 2016;79:348-57.

32. Junchao Y, Zhen W, Yuan W, et al. Anti- trachea inflammatory effects of diosgenin from Dioscorea nipponica through interactions with glucocorticoid receptor $\alpha$. J Int Med Res 2017;45:101-13.

33. Surjit M, Ganti KP, Mukherji A, et al. Widespread negative response elements mediate direct repression by agonistliganded glucocorticoid receptor. Cell 2011;145:224-41.

34. Prabhala P, Ammit AJ. Tristetraprolin and its role in regulation of airway inflammation. Mol Pharmacol 2015;87:629-38.

35. Silva RA, Almeida FM, Olivo CR, et al. Exercise reverses OVA-induced inhibition of glucocorticoid receptor and increases anti-inflammatory cytokines in asthma. Scand J Med Sci Sports 2016;26:82-92.

36. Ng Kuet Leong N, Brombacher F, Dalpke AH, et al. Crosstalk between glucocorticoids and IL-4 modulates Ym1 expression in alternatively activated myeloid cells. Immunobiology 2017;222:759-67. 
37. Clifton VL, Cuffe J, Moritz KM, et al. Review: The role of multiple placental glucocorticoid receptor isoforms in adapting to the maternal environment and regulating fetal growth. Placenta 2017;54:24-9.

Cite this article as: Zeng Z, Ma W, Zhao R, Dong X. Airway exposure to perfluorooctanoate exacerbates airway hyperresponsiveness and downregulates glucocorticoid receptor expression in asthmatic mice. Transl Pediatr 2021;10(2):323-332. doi: $10.21037 / \mathrm{tp}-20-246$
38. Wang P, Wang T, Giesy JP, et al. Perfluorinated compounds in soils from Liaodong Bay with concentrated fluorine industry parks in China. Chemosphere 2013;91:751-7. 